\title{
La economía social y solidaria en los ordenamientos jurídicos provinciales de Argentina
}

The social and solidarity economy in legal systems Provincials of Argentina

\author{
A economia social e solidária nos sistemas jurídicos \\ Provinciais da Argentina
}

\section{Miguel Agustín Torres*}

Recibido: 1 de agosto de 2018

Aceptado: 29 de noviembre de 2018

Publicado: 5 de abril de 2019

Cómo citar este artículo:

Agustín Torres, M. (2018). La economía social y solidaria en los ordenamientos jurídicos provinciales de Argentina.

Cooperativismo \& Desarrollo, 27(1), 1-27.

DOI: https://doi.org/10.16925/2382-4220.2019.01.07

Artículo de investigación.

Este trabajo se ha desarrollado con el apoyo del Consejo Nacional de Investigaciones Científicas y Técnicas de Argentina (CONICET) y de la Secretaria de Ciencia y Tecnología de la Universidad Católica de Santiago del Estero (SeCyT-UCSE). En este último caso, el trabajo se inscribe en el marco de la ejecución del proyecto de investigación "Los microemprendimientos de la economía social y su marco legal-institucional en la provincia de Santiago del Estero (Período 2012-2016). Propuestas para la elaboración de una regulación jurídica específica", aprobado y financiado por SeCyT-UCSE. https://doi.org/10.16925/2382-4220.2019.01.07

* Investigador del Consejo Nacional de Investigaciones Científicas y Técnicas de Argentina (CONICET) y del Centro de Investigaciones y Transferencia de Catamarca (CITCA - CONICET). Buenos Aires, Argentina.

Correo electrónico: agutorresk@gmail.com ORCID: 0000-0003-3410-1961 


\section{Resumen}

Introducción: en Argentina, en las últimas décadas, la economía social y solidaria fue instalándose como una alternativa de reinserción social y laboral para determinados colectivos poblaciones en situación de vulnerabilidad. No obstante, a pesar del crecimiento de esta tendencia y de la articulación de diferentes políticas oficiales destinadas a apuntalarla, la cobertura legal de los distintos aspectos implicados en la cuestión carece, aún, de un adecuado y simétrico desarrollo. Así, el escenario normativo de la economía social revela la iniciativa de algunos estados provinciales que avanzaron en el encuadre legal de la misma. Metodología: se examinan, textual y teleológicamente, los instrumentos jurídicos sobre economía social y solidaria de las provincias que avanzaron en la regulación del tema Resultados: se caracteriza el reconocimiento jurídico que recibe la economía social y solidaria en los ordenamientos provinciales de Argentina. Conclusiones: en un contexto normativo determinado por la ausencia de una ley nacional específica adquiere relevancia analizar los textos legales provinciales referentes al tema, a los efectos de describir la concepción legal de la economía social y solidaria, identificar a los actores que integran el sector e indagar en la recepción de los principios sociales y solidarios en las legislaciones provinciales.

Palabras clave: economía social y solidaria, Argentina, legislaciones provinciales, noción, actores.

\section{Summary}

Introduction: In the last decades the social and solidarity economy was installed, in Argentina, as an alternative of social and labor reintegration for certain groups of vulnerable populations. However, despite the growth of this trend and the articulation of different official policies aimed at supporting it, the legal coverage of the different aspects involved in the issue still lacks an adequate and symmetrical development. Thus, the normative scenario of the social economy reveals the initiative of some provincial states that advanced in the legal framework of the same. Methodology: the legal instruments on the social and solidarity economy of the provinces that progressed in the regulation of the subject are examined, textually and teleologically. Results: the legal recognition that the social and solidarity economy receives in the Argentine provincial systems is characterized. Conclusions: in a normative context determined by the absence of a specific national law, it is important to analyze the provincial legal texts on the subject, in order to describe the legal conception of the social and solidarity economy, to identify the actors that make up the sector and investigate the reception of social and solidarity principles in provincial legislation.

Key Words: Social and solidarity economy, Argentina, provincial legislations, notion, actors

\section{Resumo}

Introdução: Nas últimas décadas instalou-se, na Argentina, a economia social e solidária como alternativa de reinserção social e trabalhista para determinados grupos de populações vulneráveis. No entanto, apesar do crescimento dessa tendência e da articulação de diferentes políticas oficiais voltadas a apoiá-la, a abrangência jurídica dos diferentes aspectos envolvidos na questão ainda carece de um desenvolvimento adequado e simétrico. Assim, o cenário normativo da economia social revela a iniciativa de alguns estados provinciais que avançaram no marco legal do mesmo. Metodologia examina, textual e, instrumentos legais teleológicos sobre economia social das províncias avançou na regulação dos resultados questão: o reconhecimento legal recebeu solidariedade social nos sistemas provinciais de economia da Argentina se caracteriza. Conclusões: Em um contexto regulamentar determinado pela ausência de uma legislação nacional específica torna-se relevante analisar os textos legais provinciais sobre o assunto, com a finalidade de descrever o conceito legal de economia social, identificar os atores que compõem o sector e investigar a recepção dos princípios sociais e de solidariedade na legislação provincial. 
Palavras-chave: economia social e solidária, Argentina, legislação Provincial, noção, atores.

\section{Introducción}

La conformación y el desenvolvimiento de emprendimientos inscriptos en la economía social y solidaria fueron describiendo, desde el comienzo de la década pasada, una tendencia que caracteriza a la realidad socioeconómica de Argentina (García y Rofman, 2013; Castelao Caruana, 2016). Ello resulta explicable, en buena medida, debido al rol significativo que, a partir de entonces, fue adquiriendo la economía social y solidaria en el trayecto de reinserción social y laboral que describieron aquellos sujetos en situación de vulnerabilidad socioeconómica (Presta, 2016). Frente al impacto socialmente desfavorable de las políticas económicas implementadas en el país desde la última década del siglo pasado, y que culminaron en la profunda crisis económica e institucional de los años 2001 y 2002, la economía social terminó posicionándose como una vía de acción generadora de alternativas de inclusión (Coraggio, 2011).

De esta manera, en el escenario del colapso emergieron distintas respuestas desde el ámbito de la economía social. Así, en el marco de tal compleja coyuntura se asistió al surgimiento y reproducción de iniciativas de naturaleza social y solidaria, con disímiles niveles de desarrollo y, por ende, con diversas probabilidades de proyección. Este proceso de proliferación y difusión de diferentes expresiones de la economía social abarcó tanto manifestaciones poco convencionales como figuras clásicas.

La profundización de este rasgo, cuya dinámica puede explicarse desde una perspectiva sociológica, acudiendo, en cierto modo, a las interpretaciones sobre la acción colectiva, recogió el estímulo estatal a través de la implementación de diferentes programas oficiales. La ejecución de políticas dirigidas a impulsar el crecimiento de la economía social y solidaria alcanzó tanto al Estado nacional como a los ordenamientos provinciales y a los distritos municipales. Este proceso de reconocimiento estatal fue contribuyendo a la inserción institucional de la economía social y solidaria. Sin embargo, a pesar del trayecto de institucionalización desplegado, la cobertura legal del sector social y solidario carece, aún, de un desarrollo adecuado.

1 Dentro de las expresiones clásicas se destacan las cooperativas de trabajo que se incrementaron considerablemente en el escenario de recuperación que siguiera a la crisis del 2001y 2002 (Vuotto, 2011). Esta tendencia comprendió tanto a las cooperativas de trabajo voluntariamente conformadas como una alternativa al trabajo asalariado como, así también, a las denominadas "fábricas recuperadas", que suponen un esfuerzo mancomunado de rescate y conservación de la fuente laboral por parte de los propios trabajadores (Magnani, 2003; Ruggeri et al., 2017). 
Ciertamente, aunque el cooperativismo obtuvo, tempranamente, recepción normativa en el ordenamiento jurídico argentino² (Guerra, 2012), no puede predicarse lo mismo del resto de los emprendimientos pertenecientes al ámbito social y solidario 3 (Castelao Caruana, 2016). Especialmente de aquellas figuras no convencionales, de aparición relativamente reciente ${ }^{4}$. En efecto, las diferentes iniciativas que desarrollan sus actividades con sujeción a los principios y prácticas de la economía social y solidaria no cuentan con regulación específica. Durante el período comprendido entre los años 2004 y 2008 el Estado nacional promulgó tres leyes con incidencia en la dinámica social y solidaria: 1) la Ley 25865, con sus numerosas modificaciones, que implementa el Monotributo Social; 2) la Ley 26117 de Promoción del Microcrédito para el Desarrollo de la Economía Social; y 3) la Ley 26355 sobre Marcas Colectivas. No obstante, a pesar del impacto favorable, en términos institucionales, generado por estas normas, el segmento social y solidario, en el espacio nacional, requiere de un marco normativo propio.

El análisis de la cuestión dentro de las jurisdicciones provinciales no puede ser abordado, en forma consistente, sin considerar el grado de avance que exhibe el proceso de normación del tópico en el orden nacional. Precisamente, la ausencia de una ley nacional de economía social y solidaria influye, de modo determinante, en la fisonomía que ofrecen, en perspectiva comparativa, los ordenamientos provinciales ${ }^{5}$. En efecto, a pesar de que concurren normas de alcance nacional que contemplan

2 En un comienzo, las cooperativas fueron incorporadas al Código de Comercio con la reforma del año 1889. Con posterioridad, en el año 1926, se promulgó la ley nacional 11388 la cual estableció un marco legal específico. Esta norma fue reemplaza, en el año 1973, por la Ley Nacional 20337, sancionada y promulgada por el régimen de facto de aquel entonces. Esta ley, con algunas modificaciones, aún continúa vigente (Cracogna, 2013).

3 Por su parte, las asociaciones mutuales se encuentran reguladas, desde el año 1973, mediante la Ley nacional 20321, sancionada y promulgada por el gobierno de facto de aquella época. Esta norma recibió una serie de modificaciones con el transcurso de los años.

4 Pueden mencionarse, a modo de ejemplo, a los mercados asociativos, las ferias francas, las agrupaciones de consumidores solidarios, bancos éticos u organizaciones de finanzas solidarias o comercio justo, entre otros.

5 Teniendo en cuenta que en el orden nacional no se dispone, aún, de una norma de alcance general sobre el tema resulta conveniente abordar la cuestión acerca de la competencia que les asiste a las provincias para legislar en materia de economía social y solidaria. De conformidad con el artículo 121 de la Constitución Nacional (CN) las provincias se han reservado todo el poder que no han delegado al gobierno federal (art. $121 \mathrm{CN}$ ), pudiendo organizarse institucionalmente y administrarse a sí mismas (art. $122 \mathrm{CN}$ ) siempre que el despliegue de tales potestades no importe una trasgresión o un cuestionamiento a la dimensión y a las funciones que la carta política le asigna al poder federal (interferencia). Precisamente, dentro de tal reparto constitucional, la legislación de fondo en las diferentes áreas, entre ellas la referente al trabajo y a la seguridad social, configura materia privativa del gobierno nacional. A su vez, a partir de la reforma del año 1994, tanto las provincias como el estado nacional, en el ejercicio de facultades concurrentes, disponen de potestad para promover la generación de empleo (art. $125 \mathrm{CN}$ ). 
aspectos concretos del sector, el andamiaje legal conformado por esta serie de instrumentos de relevancia, lejos está de constituir un marco normativo acabado, al carecer, justamente, de una ley federal que caracterice a la economía social y solidaria, identifique sus diferentes expresiones y precise sus implicancias legales en el contexto del sistema jurídico argentino.

Si bien el Decreto 159 de 2017, reglamentario de la Ley Nacional 27345 que prorroga la emergencia económica en los términos de la Ley 27200, contribuye a visibilizar y a conferir reconocimiento legal e institucional al desenvolvimiento social y solidario. Define a la economía popular y regula algunos aspectos atinentes a la composición y funcionamiento del Consejo de la Economía Popular y el Salario Social Complementario (CEPSSC) y del Registro Nacional de la Economía Popular (RENATREP), pero no puede señalarse que haya logrado satisfacer la necesidad de regulación legal específica. Así, el citado decreto, en el artículo $2^{\circ}$ del anexo I, conceptualiza a la economía popular como "toda actividad creadora y productiva asociada a mejorar los medios de vida de actores de alta vulnerabilidad social, con el objeto de generar y/o comercializar bienes y servicios que sustenten su propio desarrollo o el familiar". Añade, además, el precepto invocado que esta variante de la economía se lleva a cabo a través de "proyectos económicos de unidades productivas o comerciales de baja escala, capitalización y productividad, cuyo principal activo es la fuerza de trabajo". Empero, más allá de esta caracterización de la economía popular, el decreto no contiene mayores referencias sobre las actividades y los sujetos del segmento social y solidario

Por otra parte, no hay una generalizada conformidad, dentro de la literatura local, sobre la exacta correspondencia entre la noción de economía popular, incluida en la invocada Ley 27345 y su decreto reglamentario, y la idea de economía social y solidaria. Para algunas posiciones (Chena, 2017) la economía popular se caracteriza por su situación de subordinación dentro de las relaciones comerciales y financieras que la conectan con la economía capitalista. Para otras posturas (Hopp y Frega, 2014), la economía popular supone un escenario fáctico definido por determinadas formas de producción e intercambio que, a partir de las intervenciones estatales y de la adopción de ciertas características en las prácticas de los trabajadores, puede conducir hacia la configuración de alternativas sociales y solidarias. Es decir, según esta visión, la economía popular implica un estadio que, eventualmente, puede orientarse hacia la economía social y solidaria. Otros enfoques, atendiendo a las condiciones y a los fines que particularizan su desenvolvimiento, entienden que la economía popular engloba a unidades económicas simples que, eventualmente, pueden servir de base para la conformación de figuras organizacionales de mayor 
complejidad. Éstas, a su vez, pueden derivar en expresiones de la economía social y solidaria (Giovannini, 2014).

En este artículo se interpreta que lo "popular" representa un rasgo que, surcando las dimensiones territorial y operacional, procura caracterizar el modo en que se despliegan las iniciativas comerciales o productivas. La economía social y solidaria, por su parte, importa la concurrencia de una serie de principios y valores que identifican al sector. Por lo tanto, los emprendimientos de naturaleza solidaria participan del carácter popular, pero ostentan y desarrollan dichos principios y valores que singularizan al segmento social y solidario. Teniendo en cuenta ello, puede señalarse que la definición contenida en el mencionado artículo 2 del anexo del Decreto 159 de 2017, si bien menciona algunos elementos que también se encuentran presentes en las expresiones solidarias, no enuncia los componentes esenciales que distinguen al sector social y solidario. En consecuencia, puede sostenerse que el referido decreto no se halla destinado a normar a las actividades de la economía social y solidaria.

En ese contexto, y a pesar de la ausencia de una ley nacional que enmarque genéricamente al espacio social y solidario, algunas provincias abordaron la regulación de la cuestión. El tratamiento normativo de esta materia en los ámbitos provinciales reviste, no obstante, un desarrollo asimétrico. Este aspecto no sólo se explica por la circunstancia de que algunas provincias dispongan de legislación específica y otras no, sino también, por la disparidad de criterios que estructuran la normación del tópico en los diferentes casos. Así, dentro de las jurisdicciones provinciales que contemplan legalmente el asunto, se registran, por una parte, experiencias de regulación específicas referentes a manifestaciones concretas de la economía social y solidaria; y por otra, supuestos en los cuales el sector social y solidario es abordado a través de dispositivos de alcance general.

Además, estas normas provinciales comportan el ensamble sistemático de los regímenes que instauran con diferentes políticas y programas destinados a impulsar las variantes de la economía social. Por ende, la realización de los propósitos que lo fundamentan abarca la interacción de diferentes actores, la intervención de distintas áreas del accionar público estatal y la participación del sector privado. Por ello, en alguna medida, la implementación de los marcos reglamentarios establecidos por estas normas se acerca a los modelos de tipo bottom up.

En atención a lo expresado en los párrafos precedentes, esta investigación se propone caracterizar el reconocimiento jurídico que recibe la economía social y solidaria en los ordenamientos provinciales de Argentina, efectuando un análisis, dentro de los marcos jurídicos correspondientes, de la noción legal de la economía social y solidaria y de la descripción normativa de los actores como mecanismo de 
delimitación del sector. Asimismo, teniendo en cuenta la relevancia que los principios y valores específicos presentan para la identificación de las expresiones de naturaleza social y solidaria, y la determinación de sus efectos, se indaga también en la recepción de los principios sociales y solidarios en las legislaciones provinciales.

En pos de tal cometido se examinan, textual y teleológicamente, los instrumentos jurídicos sobre economía social y solidaria de aquellas provincias que han avanzado en la regulación del tópico. Se analizan tanto los textos legales de alcance general: Entre Ríos (Ley 10151); Mendoza (Ley 8435); Buenos Aires (Ley 14650); Chaco (Ley 7480); como los concernientes a figuras concretas del escenario social y solidario6: Río Negro (Ley N4499-Mercados Asociativos); Buenos Aires (Ley Nº13136 de Actividades Laborales de Autoempleo y Subsistencia - Ley ALAS-.

Desde una perspectiva metodológica, este aporte constituye esencialmente un estudio de tipo descriptivo. Por tal razón, el análisis que se efectúa de los textos legales no encuadra, con precisión, en la modalidad de la interpretación comparativa, ya que el propósito de esta indagación no radica en confrontar el contenido y finalidad de los diferentes instrumentos jurídicos consultados, sino en proporcionar una descripción del escenario normativo concerniente a la economía social y solidaria en los órdenes jurídicos provinciales del Estado argentino.

\section{Noción legal}

Las regulaciones provinciales específicas, tanto los instrumentos que contemplan con alcance general el ámbito social y solidario como aquellos que se ocupan de figuras concretas del sector, definen, de forma introductoria, a la economía social y solidaria. Las caracterizaciones proporcionadas por estas normas, que contribuyen a delimitar el ámbito de aplicación de las mismas, si bien exhiben cada una de ellas sus propios matices, observan como rasgo común que las aproxima entre sí, la incorporación de referencias sobre el sentido y el propósito que explican y fundamentan la economía social y solidaria.

En este sentido, la denominada "Ley ALAS" de la provincia de Buenos Aires engloba dentro de la idea de economía social y solidaria a las actividades de contenido económico cuyo objetivo esencial consista en la reproducción de la vida, la subsistencia y el autoempleo (Ley 13,136, art. 3). Excluye de tal concepto a los emprendimientos

6 No fueron consideradas, a los fines de este análisis, la Ley III No. 10 (Decreto No. 916) de Ferias Francas de la provincia de Misiones y la Ley 2782 de Ferias Francas la provincia de Neuquén por entender que estos instrumentos abarcan aspectos que exceden el campo específico de la economía social y solidaria. 
que se hallen orientados fundamentalmente por fines de lucro y acumulación de capital (Ley 13,136, art. 4). La idea de "reproducción de la vida" acerca la noción legal a determinadas líneas de indagación ${ }^{7}$ que componen el soporte teórico específico sobre el tópico. Especialmente en el ámbito regional latinoamericano y que, precisamente, resumen con aquel concepto los fines que, a criterio de tales orientaciones, impulsan a la economía social y solidaria.

En definitiva, implica una revisión profunda de la lógica que regula el funcionamiento de la economía capitalista y, por ende, del pensamiento científico desarrollado para explicarlo y fundamentarlo. De esta manera, la reproducción de la vida cuestiona la idea de la acción racional que inspiró el pensamiento económico neoclásico al consistir esencialmente en una teoría de la relación medio-fin y terminar imponiendo una racionalidad instrumental. Por lo tanto, a partir del reconocimiento de la necesidad de introducir una interpretación que supere y trascienda tal razonamiento, se propone una "racionalidad reproductiva" (Hinkelammert y Mora Jiménez, 2009, p.41), es decir, una "racionalidad más integral de respeto al circuito natural de la vida humana" (Hinkelammert y Mora Jiménez, 2009, p.41).

Esta expresión procura condensar el significado de la economía social y solidaria como alternativa de desenvolvimiento socioeconómico confrontada con los intereses de la reproducción del capital y del poder y, por lo tanto, no sometida al servicio de la ley del valor económico. Como propósito y sentido de la economía social y solidaria, la "reproducción ampliada" requiere, para su concreción, del desarrollo de procesos de identificación de las necesidades y de la elaboración de estrategias para la gestión colectiva, en concurrencia con la apertura de instancias de diálogo y espacios de cooperación y con el despliegue de mecanismos generadores de decisiones también colectivas (Coraggio, 2011).

Para la ley de la provincia de Mendoza, del año 2012, la economía social y solidaria abarca "el conjunto de recursos y actividades, de instituciones y organizaciones" (Ley 8435, art. 2) que, orientados por "los principios de solidaridad, cooperación y autoridad legítima" (Ley 8435, art. 2), se dedican a la apropiación y disposición de recursos, "en la realización de actividades de producción distribución, circulación, financiamiento y consumo digno y responsable" (Ley 8435, art. 2). De forma semejante a la norma bonaerense, tales actividades e iniciativas son concebidas en el texto mendocino, con un significado socialmente relevante, ya que las mismas no se agotan en la búsqueda del "lucro sin límites" (Ley 8435, art. 2) sino que se dirigen a "la resolución de las necesidades de los trabajadores, sus familias y comunidades, y del medio ambiente; para lograr una sociedad más justa, inclusiva e igualitaria" (Ley 8435, art. 2).

7 Al respecto pueden mencionarse a la corriente de la economía del trabajo. 
A su vez, la ley de la provincia de Río Negro, con vigencia desde el año 2010, al establecer el régimen de promoción de los mercados productivos asociativos, considera, a través de una descripción acotada que adolece de cierta imprecisión, que las actividades enmarcadas en la economía social consisten en iniciativas basadas en el esfuerzo propio y colectivo, que generan bienes y servicios con el fin del autosostenimiento de sus respectivos núcleos familiares o de pertenencia (Ley 4499, art. 1).

Por su parte, la ley de la provincia de Entre Ríos, del año 2012, desarrolla una noción amplia de economía social y solidaria en la cual se resalta su función socialmente incluyente. Así, la economía social y solidaria comporta el accionar de personas y entidades que, a partir de una organización económica equitativa, y de modo asociativo, se abocan a la producción de bienes y servicios, a su distribución, circulación y consumo. El despliegue de estas actividades, a tenor del texto, se rige por los principios de participación democrática en el proceso de adopción de decisiones, autonomía de gestión, prevalencia del ser humano y del fin social sobre el capital; y se orienta a la consecución de la soberanía alimentaria.

Además de la amplitud que exhibe la noción legal, el precepto bajo análisis, a través de una redacción más próxima a un comentario que al estilo que debería revestir una definición convencional, introduce un lineamiento para identificar y comprender las iniciativas de índole social y solidaria y, por lo tanto, precisar el campo de aplicación de la norma. De esta manera, la ley provincial sienta que "las prácticas de estos actores se circunscriben en una conceptualización diferente de los factores de la producción, donde la solidaridad es el pilar para su funcionamiento, y su sentido no es el del lucro sin límites, sino la resolución de las necesidades de los trabajadores, sus familias y comunidades" (Ley 10151, art. 3).

Con ello, la norma destaca el carácter específico que distingue al sector social y solidario y posiciona, anticipatoriamente, en el comienzo del articulado, a los principios solidarios como parámetros de referencia para identificar a las iniciativas y procesos de naturaleza social y solidaria. Aun cuando la redacción del dispositivo legal no refleja un rigor técnico jurídico adecuado ${ }^{8}$, la invocación inicial de los principios y la importancia que les asigna no resulta desatinada ya que los mismos, por su

8 Tal cual se explicó en el párrafo que precede al referenciado, el artículo 3 de la Ley 10151 de la provincia de Entre Ríos, combina en su texto una definición legal, ubicada en la primera parte del precepto, con una redacción, situada en el fragmento final del dispositivo, que se asemeja a una leyenda interpretativa o a un comentario que revela un intento de aclaración o profundización del alcance de la noción introducida en el primer tramo del dispositivo legal. Por tal razón, puede señalarse que, técnicamente, el precepto contiene una redacción que aleja del formato convencional para esta clase de artículos que suelen iniciar el cuerpo textual de instrumentos de regulación jurídica de alcance general en una materia determinada. 
propia relevancia, ostentan virtualidad suficiente para operar como fuente necesaria de interpretación y de aplicación subsidiaria de la ley9 (García Muller, 2009).

Consideración aparte se merece la concepción de economía social que incorpora la norma específica de la provincia del Chaco, vigente a partir de noviembre de 2014, por la cual se instaura, en tal distrito, el Sistema de Promoción y Desarrollo de la Economía Social y Solidaria (Ley 7480, art. 1). Para esta ley, la economía social alude a las "formas económicas alternativas, cooperativas, autogestionarias y asociativas, basadas en la solidaridad, el trabajo y el bien común" (Ley 7480, art. 2). Si bien en una primera aproximación, la redacción podría sugerir que se trata de una noción usual y genérica, la extensión y complejidad del enfoque legal surge al abordar la descripción que, dentro del mismo artículo, ofrece la ley. Así, a continuación, en el mismo precepto se despliega una idea integral de la economía social y solidaria, abordándosela como un esquema de desarrollo que atraviesa diversas dimensiones y en cuya articulación convergen variables de distinta naturaleza. De esta manera, la economía social y solidaria es concebida como un:

[...] sistema socioeconómico, cultural y ambiental conformado por el conjunto de recursos y actividades, personas, instituciones y organizaciones, que operan según principios de desarrollo integral del ser humano como sujeto, actor y fin de la economía, fomentando las estrategias de desarrollo: la gestión del conocimiento, formación, innovación, redes y desarrollo local a efectos de lograr una sociedad inclusiva e igualitaria (Ley 7480 , art. 2).

La norma recoge un concepto global de la economía social y solidaria que denota la influencia de una visión con marcado anclaje en reconocidos sectores especializados (García Muller, 1998; Collin Harguindeguy). Este enfoque sistémico que admite diferentes matices según las interpretaciones implica, a modo de contracultura, un modelo de crecimiento económico que se conjuga con un patrón de funcionamiento social.

Desde esta concepción integral, la propuesta social y solidaria no se restringe a la introducción de opciones o vías de acción que morigeren los efectos de la economía

9 Añade, además, García Müller (2009), que, debido a su elevado grado de desarrollo, el derecho cooperativo propiamente dicho podría constituir fuente supletoria a la hora de cubrir las lagunas normativas que se pudieran emerger en la aplicación de los derechos mutuales y solidarios. Efectivamente, el derecho cooperativo, en virtud del que presenta, materializado a través de un consistente marco legal y de la acumulación de destacadas contribuciones doctrinarias y jurisprudenciales, configura, en muchos escenarios normativos, la parcela de la economía social de mayor perfeccionamiento jurídico. El ordenamiento jurídico argentino reproduce, en este tópico, tal descripción. 
capitalista, por el contrario, aquella consiste en principios y valores diametralmente antagónicos a las "prácticas excluyentes, social y ambientalmente predatorias" (Cattani, 2009, p.7) generadas por el capitalismo. Inspirado por los principios de solidaridad, sustentabilidad, inclusión y emancipación social ${ }^{10}$, la economía social y solidaria supone una alternativa material y humanamente distinta frente a la desigualdad emergente de las relaciones de producción capitalista.

En esta dirección, la economía social y solidaria le permite a Mance (2001) entrever la posibilidad de una sociedad poscapitalista. La articulación y la sinergia de redes que enlacen unidades de producción y consumo ${ }^{11}$ (Mance, 2001) de naturaleza social y solidaria tornarían factible la instauración de tal instancia, al conformar un escenario incluyente, caracterizado por el suministro de empleo y el incremento de la renta, que desencadenaría una transformación cultural de las sociedades "con la afirmación de una ética y de una visión de mundo antagónicas no sólo al Neoliberalismo sino al propio capitalismo" (Mance, 2001, p.173). En su parecer, la conformación de redes de colaboración solidaria, a escala local, regional y mundial, proporcionarían "una alternativa viable poscapitalista a la globalización en curso generando empleo y distribución del ingreso y promoviendo el crecimiento ecológico y socialmente sustentable" (Mance, 2001, p.165). El trayecto hacia una etapa poscapitalista habría de consistir en "una nueva organización económica, política y cultural" (Mance, 2001, p.166) y no simplemente en "ajustes del modelo capitalista ante una nueva situación de la globalización económica, una vez que se contraponen a los principios y parámetros del capitalismo" (Mance, 2001, p.147).

A su vez, García Müller interpreta también a la economía social y solidaria como un sistema que transcurre más allá de lo económico para extenderse a los ámbitos social, político y cultural, y en cuya organización participan cinco rasgos fundamentales (García Müller, 1998) que coinciden con los contenidos que, usualmente, suelen calificarse como principios solidarios. De este modo, la cooperación y la solidaridad

10 Emancipación social es una idea y un concepto trabajado, con destreza, por Cattani (2009).

11 Según Mance, el consumo solidario "ocurre cuando la selección de lo que consumimos es hecha no sólo considerando nuestro bien-vivir personal, sino también el bien-vivir colectivo, una vez que es en el consumo que la producción se completa y que este tiene impacto sobre todo el ecosistema y sobre la sociedad en general. En otras palabras, las elecciones de consumo influencian tanto en la generación o sustento de puestos productivos en una dada sociedad -cuando consume lo productos elaborados en ella-, en la preservación de ecosistemas -cuando se consumen productos de empresas que adoptan el reciclaje de materiales, el combate a la polución, etc. - en fin, en la promoción del bien-estar colectivo de la población de una comunidad, de su país y de su planeta. Por otra parte, las elecciones de consumo también pueden generar desempleo local, colaborar en la destrucción de ecosistemas y en la extinción de especies vegetales y animales, en la producción cada vez mayor basura no biodegradable, en el aumento de la polución y en el empeoramiento de la calidad de vida de la población y de su comunidad, de su país y del planeta como un todo" (Mance, 2001, p. 167) 
tanto en el trabajo como en la base de la convivencia, la prevalencia del trabajo sobre el capital, la propiedad social, recayendo sobre los trabajadores, de los medios de producción y la autogestión del emprendimiento, convergen en el pensamiento del autor, para constituir una opción transformadora de las estructuras socioeconómicas imperantes y ofrecer, de tal forma, una variante al planteo capitalista. Su comprensión del proceso social y solidario se encuentra imbuida de una marcada impronta democrática, en donde la conjunción de los componentes descriptos conduciría hacia la consolidación de la democracia real ${ }^{12}$.

\section{La identificación de los actores. Su aporte al reconocimiento legal del sector}

La identificación y descripción de los diferentes actores que pueden ser incluidos dentro de la economía social y solidaria constituye un aspecto que se reproduce en los dispositivos normativos locales en la materia. El sentido que adquiere este proceso de distinción e individualización de los sujetos de la economía social puede ser apreciado desde dos ángulos de análisis. Desde un estricto enfoque técnico, referido al ámbito de cobertura jurídica, donde puede señalarse que la enunciación legal de los agentes que conforman la economía solidaria obedece al propósito de precisar el alcance de la norma y delimitar su campo de aplicación. Pero, a su vez, desde una perspectiva institucional, entendida en un sentido amplio, donde puede afirmarse que tal proceso de individualización contribuye a la caracterización del sector social y solidario.

Ciertamente, la demarcación conceptual de la economía social y solidaria que los textos legales específicos procuran introducir no se circunscribe a la definición contenida en los mismos. Así, el segmento social y solidario también puede comprenderse a través de la consideración de los actores que lo protagonizan y de

12 En tal sentido, para García Müller la economía social constituye un "sistema económico, social, político y cultural, sustentado en cinco principios fundamentales: a) la solidaridad, la cooperación y la democracia como forma de vida y convivencia humana; b) la supremacía del trabajo sobre el capital, con lo cual se reencuentra el origen del desarrollo humano y se rescata el trabajo de la esclavitud del capital; c) el trabajo asociado como base fundamental de la organización de la producción y de la economía, con lo cual se elimina el trabajo salariado como expresión de la cultura capitalista y la causa principal de la injusta distribución de la riqueza; d) la propiedad social de los medios de producción donde los trabajadores como productores directos son los propietarios y gestores de la empresa y beneficiarios plenos de los beneficios económicos, con lo cual se elimina la explotación del hombre por el hombre, del hombre por el Estado y la causa fundamental de la lucha de clases; e) la autogestión como forma superior de participación de los trabajadores en la gestión de la empresa, la economía y en la conducción del Estado y la sociedad, con lo cual se elimina la marginalidad y se construye y consolida la democracia real" (1998, p. 261). 
los diferentes circuitos de interacción que se generan entre ellos. Pues el accionar de los sujetos que la componen se encuentra inspirado en los valores que fundamentan el modelo solidario y sustentado en los principios que lo orientan. Tal como señala Meira (2013), al examinar la ley portuguesa de economía social, el sector se identifica, en términos legales, por la actividad realizada - socioeconómica-; el objeto perseguido - búsqueda de un interés general- y el sujeto que la realiza - una entidad solidaria-.

Por lo tanto, los intentos de caracterización normativa de la economía social y solidaria no pueden prescindir de las referencias a las notas distintivas de las actividades que pueden englobarse en esta orientación como, tampoco, a los rasgos que determinan la fisonomía que deben revestir los protagonistas del escenario social y solidario. Así, la conceptualización de la economía social contenida en las leyes específicas, lejos de limitarse a las definiciones que proporcionan, debe ser abordada a partir de una interpretación amplia y sistemática de los diferentes aspectos preceptuados en aquellas, en pos de alcanzar una completa construcción conceptual de la economía social y solidaria.

\section{El contexto normativo}

La caracterización legal de los actores que conforman el sector social y solidario se efectúa a través de una modalidad dual, consistente, por una parte, en la descripción de los lineamientos generales que deben reunir los mismos para considerarse enmarcados dentro de la economía social, y, por otra parte, también en la enunciación de las formas organizativas que pueden revestir tal carácter. Ambos tipos de menciones, en mayor o menor medida, se encuentran atravesadas por remisiones a los valores y principios que configuran el sustrato del desenvolvimiento social y solidario.

La incorporación de aquellos lineamientos, que aluden a las notas que deben concurrir en la clase de actividad productiva o comercial que se lleva a cabo, operan como pautas de identificación del accionar solidario y revisten un carácter genérico y subsidiario frente a la enumeración de las distintas expresiones que puede asumir la economía social. De este modo, las iniciativas citadas en los preceptos legales no pueden desplegar un obrar que se aparte o cuestione el significado de tales pautas.

Así, en la Ley 8435 de la provincia de Mendoza, la economía social y solidaria se encuentra protagonizada por aquellos sujetos que dispongan de una administración democrática y participativa, y un reparto equilibrado de la renta generada, garantizado a través de una organización económicamente equitativa y una justa asignación de recursos, ingresos y beneficios (Ley 8435, art 3). La labor de tales 
emprendimientos no debe concentrarse exclusivamente en la producción y consumo o venta de bienes y servicios, sino que debe tender a la humanización de los lazos sociales (Ley 8435, art 3).

A continuación de esta descripción inicial de los rasgos que distinguen y especifican a los sujetos que observan prácticas sociales y solidarias, la norma ilustra la caracterización brindada, detallando una serie de iniciativas que integran el ámbito social y solidario. De este modo, según tal enunciación legal, que resulta ratificada por el Decreto 2.266 de 2013, reglamentario de la norma citada, el escenario social y solidario se compone de:

- Personas jurídicas como -cooperativas, mutuales, asociaciones civiles, organizaciones vecinales, organizaciones de microcrédito, organizaciones campesinas, organizaciones de agricultura familiar, empresas recuperadas, comercializadoras solidarias, organizaciones solidarias, organizaciones indígenas-.

- Grupos asociativos legitimados -ferias populares, clubes del trueque, centros de estudios e investigaciones-.

- Personas físicas - microemprendedores vinculados y efectores de desarrollo local y economía social- (Ley 8435, art 3).

La Ley 10151 de la provincia de Entre Ríos caracteriza a los actores de la economía social a partir de la concurrencia de una serie de notas que implican referencias tanto al modo de gestión como al contexto en el cual se desenvuelven. Subyace a tal descripción el reconocimiento de la potencialidad incluyente de las iniciativas sociales y solidarias. De esta forma, la economía social se integra por las personas físicas o los grupos asociativos que, enfrentando un contexto de vulnerabilidad social, se organicen a partir de la gestión del autoempleo para realizar actividades de producción, de manufacturas, o comercialización de bienes o servicios, urbanos o reales o, en su caso, que posibiliten la reinserción laboral de discapacitados (Ley 10151, art. 4). No obstante esta descripción de amplio alcance, la norma enumera las figuras cuyo desenvolvimiento fáctico configuran el segmento social y solidario.

- Las cooperativas de trabajo.

- Mutuales, asociaciones civiles, fundaciones.

- $\quad$ Agrupaciones de microemprendedores, emprendimientos comunitarios.

- Clubes del trueque, ferias y mercados asociativos populares, redes de comercio justo. 
- Organizaciones de microcrédito, bancos populares.

- Empresas recuperadas, redes de consumo organizaciones libres del pueblo sin fines de lucro (Ley 10151, art. 4).

Se destaca la incorporación que realiza la norma de la idea de vulnerabilidad social para aludir, en forma general, a los factores que condicionan la reinserción sociolaboral y las alternativas que, frente a tal cuadro, la economía social y solidaria puede proporcionar. Precisamente, la noción de vulnerabilidad se refiere a "las características de una persona o grupo y su situación, que influencian su capacidad de anticipar, lidiar, resistir y recuperarse del impacto de una amenaza" (Wisner, et al., 2004, p.11). De esta forma, la vulnerabilidad supone siempre la eventualidad de un riesgo, la concurrencia de una amenaza. En este supuesto, teniendo en cuenta que se alude a condiciones sociales, el factor amenazante procede de la complejidad del propio contexto que el sujeto debe surcar y de los recursos con los cuales cuenta para afrontarlo. La amenaza está dada por el riesgo que comporta el avance de una situación de exclusión social.

Por su parte, según la Ley 14650, de la provincia de Buenos Aires, la economía social se compone de las personas o grupos asociativos organizados a partir de la gestión del autoempleo (Ley 14650, art. 3), cuyo accionar se ajusta a los principios de solidaridad, cooperación y autoridad legítima (Ley 14650, art.2). El accionar de tales sujetos, debe dirigirse a "la realización de actividades de producción, distribución, circulación, financiamiento y consumo digno y responsable" (Ley 14650, art.2), reconociendo su sentido en "la resolución de las necesidades de los trabajadores, sus familias y comunidades, y del medio ambiente; para lograr una sociedad más justa, inclusiva e igualitaria" (Ley 14650, art.2).

Empero, a pesar de esta descripción de alcance general, la Ley 14650 también contiene una enunciación de las expresiones de la economía social y solidaria. Así, de conformidad con el texto legal, la economía social y solidaria comprende las siguientes entidades, en la medida en que su proceder se adecue a las pautas mencionadas. A saber:

- $\quad$ Cooperativas de trabajo.

- Mutuales, asociaciones civiles, fundaciones.

- Agrupaciones de microemprendedores.

- Emprendimientos comunitarios.

- Redes de comercio justo. 
- Organizaciones de microcrédito, bancos populares.

- Clubes del trueque, ferias y mercados asociativos populares.

- Empresas recuperadas.

- Redes de consumo responsable.

- Organizaciones libres del pueblo.

La Ley 7480 del Chaco, del año 2014, adopta una fórmula semejante a la contenida en la norma bonaerense para identificar a los sujetos de la economía social y solidaria. De esta manera, según el texto normativo del Chaco, el sector social y solidario se integra por los actores que enumera, en la medida en que el accionar de los mismos se despliegue de conformidad con "los principios de desarrollo integral del ser humano como sujeto, actor y fin de la economía" (Ley 7480, art. 2). Así, la norma del Chaco califica como actores de la economía social y solidaria a:

- Las personas físicas o grupos asociativos.

- Cooperativas de trabajo.

- Mutuales, asociaciones civiles, fundaciones.

- Agrupaciones de microemprendedores, emprendimientos comunitarios.

- Clubes del trueque, ferias, mercados asociativos populares.

- Organizaciones de microcrédito, bancos populares.

- Empresas recuperadas.

- $\quad$ Redes de consumo responsable (Ley 7480, art. 3).

Estas normas, en lo concerniente a la identificación y descripción de los actores de la economía social y solidaria, parecieran incurrir en una contradicción, al describir en un principio pautas generales de caracterización y, luego, proceder a enunciar tipologías de figuras sociales y solidarias. Sin embargo, puede sostenerse que la redacción de los respectivos preceptos involucrados observa un carácter abierto, con el propósito de incluir a las diferentes alternativas de la economía social que pudieran conformarse y desarrollarse. Tal sentido conferido a la identificación legal de los componentes del sector social y solidario se aproxima a la posición esgrimida por algunos autores.

Así, en esta dirección, García Muller interpreta que una política de desarrollo de la economía social y solidaria:

[...] en términos generales, las normas jurídicas de la Economía Social o Solidaria deberían caracterizarse por: [...] su amplitud y flexibilidad: esto es, abarcar las más diferentes, inéditas y autóctonas formas asociativas 
de la Economía Solidaria o Social, evitando enumeraciones taxativas, disposiciones rígidas o estructuras estrictas. Deben ser, a la vez, normas lo suficientemente restrictivas que excluyan las pseudo empresas y lo bastante amplias para que puedan aplicarse a todo tipo de empresa social o solidaria. (2009, p.50).

En sintonía con tal postura, Coraggio, apunta que:

[...] no tiene formas institucionales prototípicas fijas — como las cooperativas-, sino que debe estar abierta a la diversidad cultural, la reafirmación o re-significación de formas tradicionales —como las comunidades- o la emergencia de nuevas formas - como las redes_. La legislación debe reflejar esta apertura respecto a un proceso abierto a la innovación y no tipificar e institucionalizar demasiado pronto las nuevas formas ni avanzar con la modernización de las que han sobrevivido por siglos —como las formas de patrimonio y usufructo-. (2011, p. 407).

\section{Los principios sociales y solidarios. Caracterización y relevancia}

La economía social y solidaría, en los alcances que las distintas interpretaciones le confieren, constituye un sector en cuyo desenvolvimiento convergen un complejo de valores, un conjunto de criterios y una serie de fines que la singularizan y contribuyen a diferenciarlas de las expresiones de la economía capitalista. Estos componentes, que concurren a explicar e identificar a las iniciativas inscriptas en aquella orientación, configuran los principios rectores que definen a la economía social y solidaria.

La relevancia y la función identitaria de los principios se encuentran presentes tanto a lo largo del trayecto que describió el proceso de reconocimiento de la economía social como del recorrido que experimentó el proceso de construcción de conocimiento en este campo. De esta manera, la Conferencia Europea Permanente de Cooperativas, Mutualidades, Asociaciones y Fundaciones (CEP-CMAF), espacio representativo de las entidades de la economía social dentro del espacio europeo, adoptó la Carta de Principios de la Economía Social, declaración que consagra los valores esenciales del movimiento social y solidario, delimita conceptualmente a las empresas que lo conforman (Monzón, 2007) y, de esta forma, las diferencia de las empresas capitalistas y las empresas públicas (Fajardo García, 2012). De conformidad 
con el documento citado, la plataforma de principios se integra con las siguientes características:

- Primacía de la persona y del objeto social sobre el capital.

- Adhesión voluntaria y abierta.

- Control democrático por sus miembros -excepto para las fundaciones que no tienen socios-.

- Conjunción de los intereses de los miembros usuarios y del interés general.

- Defensa y aplicación de los principios de solidaridad y responsabilidad.

- Autonomía de gestión e independencia respecto de los poderes públicos.

- Destino de la mayoría de los excedentes a la consecución de objetivos a favor del desarrollo sostenible.

- Desarrollo sostenible, del interés de los servicios a los miembros y del interés general.

Estos principios fueron rescatados y reproducidos tanto en el ámbito europeo como en otros escenarios. En el despliegue de los procesos de institucionalización de la economía social los principios fueron incorporándose a los programas de promoción del sector y a los marcos normativos específicos. La recepción de los principios en las estructuras legales e institucionales da cuenta de la significación que los mismos adquieren para la caracterización de la economía social y solidaria y la identificación de sus agentes.

Empero, a pesar de la inserción de estos principios en distintos regímenes jurídicos en la materia y del tratamiento que los mismos han recibido en el curso del desarrollo teórico de la economía social, algunas posiciones dentro de la literatura específica, sostienen la conveniencia de:

[...] indagar si estos principios ostentan el carácter de universales, o subcontinentales, o si, por el contrario, cada país, dentro de su normatividad o criterios doctrinales y jurisprudenciales, estructura en ocasiones diferentes nociones y conocimientos que impidan convertir en tesis estos principios (Katime Orcasita y Sarmiento, 2006, p. 66).

Reflejando en cierta medida proximidad con tal opinión, García Müller considera que la fisonomía de los principios sociales y solidarios en Latinoamérica no se ajusta con precisión a la manifestación que presentan en el ámbito español (2014). A su parecer, la versión española concuerda, en términos generales, con la enunciación propuesta en la mencionada Carta de Principios de la Economía Social. En relación a 
Latinoamérica, luego de sostener que la economía social y solidaria se sustenta en los valores de igualdad, mutualidad, cooperación, solidaridad, honestidad, transparencia y equidad, señala que se funda en una serie de principios que califica de generales, y consisten en:

- La composición absoluta o prevaleciente de trabajadores.

- La afiliación voluntaria, la democracia participativa y la autogestión.

- La propiedad solidaria de los medios de producción, el trabajo asociado y el predominio del trabajo sobre el capital.

- La integración y la articulación funcional y operativa en todos sus niveles.

- El beneficio directo de sus miembros, el constante interés por la comunidad y su preocupación por la preservación del medio ambiente.

Como se mencionó, los principios de la economía social, además de resumir los fines de la misma, suponen criterios o pautas referentes al funcionamiento de la iniciativa social y solidaria. Así, y teniendo en cuenta que el emprendimiento de naturaleza solidaria debe coexistir en términos de producción con empresas capitalistas, puede afirmarse, siguiendo a Gaiger (2008, p.20) que el desempeño de aquella "depende decisivamente de la integración positiva entre sus principios solidarios y participativos y las soluciones adoptadas con miras a la eficiencia económica" (2008, p. 20).

\section{Inserción legal}

La Ley 8435 de Mendoza, sancionada en el año 2012, que instaura en esa provincia el Programa de Promoción de la Economía Social, incluye las referencias a los principios dentro de la construcción conceptual de la economía social y solidaria que instituye. Para esta norma, el escenario social y solidario requiere de la concurrencia de los principios de solidaridad, cooperación y autoridad legítima como fundamento de los recursos, actividades, organizaciones e instituciones que describen un circuito de producción, distribución, financiamiento y consumo responsable, con el propósito de resolver las necesidades de los trabajadores, sus familias y de las comunidades a las cuales pertenecen (Ley 8435, art. 2).

La orientación social y solidaria impone que este ciclo de producción, comercio y consumo, desplegado con resguarde del medio ambiente, tienda a la concreción de una sociedad más justa e igualitaria y, por ende, más inclusiva (Ley 8435, art. 2). Los principios sociales y solidarios también son invocados en la norma para caracterizar a los protagonistas del sector. Así, para esta ley, el sector se compone de sujetos 
que observan una gestión democrática y participativa (Ley 8435, art. 3), cuentan con una organización económicamente equitativa (Ley 8435, art. 3), respeta una justa distribución de los recursos, ingresos y beneficios (Ley 8435, art. 3).

A su vez, la Ley 10.151 de la provincia de Entre Ríos, vigente desde el año 2012, incorpora también a los principios sociales y solidarios, asignándoles un sentido medular en la edificación del régimen jurídico e institucional. Los principios atraviesan tanto los objetivos que la norma debe procurar alcanzar, como la concepción de la economía social que alberga la ley. Dentro de los objetivos enunciados en el texto legal indica que los principios de igualdad, solidaridad, autogestión, ayuda mutua y justicia social deben sustentar los valores sociales que pretende impulsar (Ley 10151, art. 2). Los principios sociales y solidarios nutren el espíritu que inspira la visión de la economía social y solidaria que la norma abraza.

De esta manera, en una definición amplia de la economía social y solidaria, los principios de actuación asociativa, reparto equitativo en la organización económica, adopción democrática de decisiones, autonomía de gestión, primacía del ser humano (Ley 10151, art. 3) y del fin social sobre el capital deben regir "el conjunto de actividades orientadas a la producción de bienes y servicios, a su distribución circulación y consumo" (Ley 10151, art. 3). Los principios también se hallan mencionados en la conexión que la norma efectúa entre la economía solidaria y la inclusión social al destacarse que este segmento se compone de "personas físicas o grupos asociativos en situación de vulnerabilidad social, que se organicen en torno a la gestión del autoempleo, en un marco de economía justa y solidaria" (Ley 10151, art. 4).

La observancia y realización de los principios inciden en la configuración del sector social y solidario, como ámbito de desenvolvimiento económico que propone una alternativa diferente frente a los efectos del capitalismo de mercado, pues en el parecer del legislador:

[...] las prácticas de estos actores se circunscriben en una conceptualización diferente de los factores de la producción, donde la solidaridad es el pilar para su funcionamiento, y su sentido no es el del lucro sin límites, sino la resolución de las necesidades de los trabajadores, sus familias y comunidades (Ley 10151, art. 3).

La Ley 7480, de la provincia del Chaco, también enlaza los principios sociales y solidarios con la noción legal de la economía social y con la caracterización de los sujetos que integran este campo. Ello supone que, de conformidad con el texto legal, los principios proporcionan criterios para comprender el funcionamiento del sector e 
individualizar a sus agentes. De esta manera, los principios integran la definición de la economía social y solidaria, la cual, según la inteligencia de la norma, comprende "a las formas económicas alternativas, cooperativas, autogestionarias y asociativas, basadas en la solidaridad, el trabajo y el bien común" (Ley 7480, art. 2). La visión sobre la economía social y solidaria que recoge esta norma se destaca por su amplio alcance y su enfoque sistémico. De esta manera, tal como se mencionó en lo referente a la noción legal, en el régimen inaugurado por la ley "chaqueña", la economía solidaria es asimilada a un sistema de múltiples dimensiones -socioeconómico, cultural y ambiental- en el cual las personas, las instituciones y organizaciones promueven y realizan las estrategias de desarrollo (Ley 7480, art. 2).

[...] un sistema socioeconómico, cultural y ambiental conformado por el conjunto de recursos y actividades, personas, instituciones y organizaciones, que operan según principios de desarrollo integral del ser humano como sujeto, actor y fin de la economía, fomentando las estrategias de desarrollo: la gestión del conocimiento, formación, innovación, redes y desarrollo local a efectos de lograr una sociedad inclusiva e igualitaria.

La perspectiva sistémica de la economía social y solidaria que inspira a la norma se aproxima al enfoque sostenido por un sector de la literatura específica. En tal dirección puede citarse a García Müller (2009), quien interpreta también a la economía social y solidaria como un sistema que transcurre más allá de lo económico para extenderse a los ámbitos social, político y cultural, y en cuya organización participan cinco rasgos fundamentales, que coinciden con los contenidos que, usualmente, suelen calificarse como principios solidarios.

De este modo, la cooperación y la solidaridad -tanto en el trabajo como en la base de la convivencia-, la prevalencia del trabajo sobre el capital, la propiedad social recayendo sobre los trabajadores de los medios de producción y la autogestión del emprendimiento, convergen, en el pensamiento del autor, para constituir una opción transformadora de las estructuras socioeconómicas imperantes y ofrecer, de tal forma, una variante al planteo capitalista. Su comprensión del proceso social y solidario se encuentra imbuida de una marcada impronta democrática, en donde la conjugación de los componentes descriptos conduciría hacia la consolidación de la democracia real (García Müller, 2009).

De modo semejante puede invocarse la posición esgrimida por Coraggio quien caracteriza a la economía social y solidaria como: 
[...] el sistema histórico de instituciones, valores y prácticas —recurrentes, por costumbres, por eficacia comprobada, jurídicas - mediante el cual cada comunidad, conjunto de comunidades o sociedad, organiza y coordina el proceso económico cuyos momentos son: (i) La producción racional de bienes y servicios bajo una pluralidad de formas de organización en el marco de un sistema de división social del trabajo según el principio de complementariedad, con la cooperación predominantemente autónoma/autogestiva entre trabajadores, con acceso a los medios de producción y los conocimientos, en relación restitutiva entre trabajo y naturaleza [...]; (ii) La distribución y redistribución de la nueva riqueza producida [...]; (iii) El intercambio justo entre personas, sectores y regiones con predominio de la reciprocidad por sobre la competencia-con áreas de autarquía a diversos niveles —familiar, comunitario, local, nacional, regional-; (iv) Los modos de consumo responsable con la naturaleza y la convivencia social [...]; (v) La coordinación consciente y democrática del conjunto del proceso económico, combinando formas de decisión colectiva o mecanismos como el de mercado regulado (2016, pp. 18-19).

Por su parte, la Ley 14650 de la provincia de Buenos Aires promulgada en el año 2014 describe a la economía social y solidaria como "la estrategia de desarrollo basada en la promoción y fomento de relaciones económicas con perspectiva de derechos humanos, en las que debe primar la dignidad de las personas" (Ley 14650, art. 2). De esta forma se introduce en la definición algunos valores que, a criterio del legislador, singularizan a la práctica social y solidaria. Así, la misma supone un desenvolvimiento económico que, armonizando con los derechos humanos, enaltezca la dignidad humana (Ley 14650, art. 2).

Luego de esta definición, proporcionada ab initio, la norma bonaerense incorpora los principios sociales y solidarios, empleando el mismo estilo que la ley de Mendoza. Acude, en consecuencia, a los principios para completar la caracterización de la economía social, utilizando una redacción similar a la contenida en el texto mendocino. Por ende, califica como principios a la solidaridad, la cooperación y a la autoridad legítima (Ley 14650, art. 2), los cuales deben fundar e impulsar un tipo de organización y producción orientados a resolver las necesidades de los trabajadores, su grupo familiar y de las comunidades en donde se integran con el propósito de contribuir a la conformación de un entorno social inclusivo e igualitario (Ley 14650, art. 2). 
Estos principios son reiterados al momento de enunciarse los objetivos de la ley. Así, entre otros, la ley bonaerense, reconoce como objetivos el incentivo a los valores sociales "basados en la igualdad, la solidaridad, la autogestión, la ayuda mutua y la justicia social" (Ley 14650, art. 4, inc. c) en la medida en que promuevan "la construcción de comunidad y la organización popular" (Ley 14650, art. 4, inc. c).

\section{Conclusiones}

Tal cual se comentó en el transcurso de este artículo , pueden distinguirse, dentro de los ordenamientos provinciales del Estado argentino, dos modalidades de acción institucional para afrontar el proceso de configuración de un marco legal específico para la economía social y solidaria. Así, algunas jurisdicciones provinciales avanzaron en la regulación de la economía social y solidaria a través de normas que, con carácter genérico, abordan aspectos estructurantes del tópico. Otras, en cambio, emprendieron el trayecto de construcción del régimen legal en este ámbito a través del tratamiento normativo de determinadas figuras sociales y solidarias. Según pudo interpretarse en esta investigación, un abordaje genérico de la cuestión posibilita la elaboración de una concepción normativa de la economía social y solidaria de alcance general, ajustable a las diferentes iniciativas comprendidas en este campo.

Como pudo advertirse, las normas específicas analizadas revisten un carácter iniciático en la materia. De eso da cuenta la propia redacción de algunos preceptos, dirigidos no sólo a caracterizar al sector propio de la economía social y solidaria sino también a explicar en qué consiste el mismo. Es decir, cuáles son los fines y fundamentos de las actividades que deben describir los sujetos que componen el segmento social y solidario. Asimismo, corresponde señalar que, en diferente medida, los instrumentos legales examinados reconocen que la economía social importa un aporte comunitario relevante al operar como un mecanismo social con virtualidad incluyente.

Respecto a los actores que conforman el sector social y solidario puede afirmarse, de conformidad con el examen efectuado, que el proceso de caracterización legal de los sujetos permite resaltar los siguientes aspectos:

- El carácter horizontal, en sentido amplio, que presentan las relaciones entre los miembros. La participación equitativa de los mismos es una de las notas más distintivas de estas iniciativas y, a la vez, sintoniza con los propósitos de la economía social. 
- El criterio democrático que inspira y estructura la interacción de los integrantes en el ámbito de la administración del emprendimiento social y solidario.

- El accionar de los sujetos en el marco del emprendimiento social persigue, además de la autogestión y la propia sustentabilidad, la consolidación de los lazos sociales recíprocos. De este modo, los textos legales recogen la idea de que las prácticas sociales y solidarias resultan conducentes a una mayor sociabilidad, contribuyendo a arraigar, en la comunidad, los principios de la solidaridad y la cooperación.

Por su parte, en relación a la recepción de los principios sociales y solidarios en los textos legales analizados puede destacarse lo siguiente:

- Las normas estudiadas contienen enunciaciones directas y expresas de los principios sociales y solidarios. Tal mención resulta funcional respecto al propósito de introducir definiciones y lineamientos que pudieran servir para fijar las pautas centrales del encuadre legal e institucional de la materia.

- Las legislaciones provinciales consultadas le asignan a los principios sociales y solidarios un sentido relevante en la tarea de delimitación de la economía social y solidaria y en la labor de identificación de los actores comprendidos en el sector. Por tal razón, los principios integran las concepciones de la economía social y solidara que inspiran y fundamentan los instrumentos estudiados.

- Del mismo modo, la incorporación de los principios contribuye al proceso de demarcación del ámbito de desenvolvimiento efectivo de la dinámica social y solidaria, pues aquellos constituyen una referencia al momento de determinar los sujetos que podrían conformar el sector.

- Asimismo, en un estricto sentido técnico jurídico, puede sostenerse que los principios también colaboran en la labor hermenéutica, puesto que suministran específicos criterios de interpretación normativa en aquellos supuestos en que la aplicación del texto legal admita, eventualmente, posiciones contradictorias.

Por último, resulta útil apuntar que los dispositivos legales provinciales reflejan puntos de contacto. Así, revelan proximidad en lo atinente a los fines que los inspiran y a los objetivos procurados. Del mismo modo, importan la instauración de regímenes amplios dirigidos no solo a caracterizar a la economía social y solidaria y a tipificar las iniciativas que pueden inscribirse dentro de ella, sino, también, a establecer 
el diseño institucional específico, adecuado para garantizar el desempeño de las distintas alternativas comprendidas en el sector. Así, los beneficios previstos en los marcos legales y los canales institucionales cuya articulación presuponen aquellos, evidencian la consideración de algunos elementos fácticos que suelen restringir el desenvolvimiento de las iniciativas de naturaleza social y solidaria.

\section{Referencias}

Castelao Caruana, M. E. (2016). Las políticas públicas y su visión de la economía social y solidaria en Argentina. Revista Mexicana de Ciencias Políticas y Sociales, 61 (227), 349-378.

Cattani A. (2009). Construindo a Outra Economia. En A. Cattani, J. Laville, et al. Dicionário internacional da outra economia. Coimbra: Almedina.

Chena, P. (2017). La economía popular y sus relaciones fundantes. En E. Pérsico, et al. Economía Popular: los desafíos del trabajo sin patrón. Buenos Aires: Colihue.

Collin Harguindeguy, L. (2008). La Economía Social y Solidaria. Pasos (Segunda Época), 135, 2-12.

Coraggio, J. (2011a). Economía Social y Solidaria. El trabajo antes que el capital. Quito: Abya Yala..

Coraggio, J. (2011b). El papel de la economía social y solidaria en la estrategia de inclusión social. Decisio, 29, 23-31.

Coraggio, J. (2016). La economía social y solidaria (ESS): niveles y alcances de acción de sus actores. El papel de las universidades. En C. Puig (Coord.). Economía Social y Solidaria: conceptos, prácticas y políticas públicas. Bilbao: Universidad del País Vasco.

Cracogna, D. (2013). Las cooperativas y su dimensión social. Pensar en Derecho, 3 (2): 209-229.

Fajardo García, I. G. (2012). El concepto legal de economía social y la empresa social. Revista Vasca de Economía Social, 8, 63-84.

Gaiger L. (2008). Brasil: un retrato de la lucha emancipatoria de los pobres. Otra Economía, I/(2), $17-20$.

García Müller, A. (1998). Marco Jurídico de la economía Social en Latinoamérica. DIKAIOSYNE, 1, 259-291. 
García Müller, A. (2009). Marco legal de la economía social o solidaria según el Movimiento de los Trabajadores de América Latina. RIDAA, 55, 47-67.

García Müller, A. (2014). Derecho Cooperativo y de la Economía Social y Solidaria, Asociación Iberoamericana de Derecho Cooperativo, Mutual y de la Economía Social y Solidaria. Mérida.

García, A. y Rofman, A. (2013). Economía solidaria en argentina. Definiciones, experiencias y potencialidades. Revista Atlántida, 3, 99-118.

Giovannini, M. (2014). De la Economía Popular a la Economía Social y Solidaria: el Caso de los Recicladores de Base en Santiago de Chile. Euricse Working Papers, 73 (14), 1-17.

Guerra, P. (2012). Las legislaciones sobre economía social y solidaria en América Latina. Entre la autogestión y la visión sectorial. Revista de la Facultad de Derecho, 33, 73-94.

Hinkelammert, F. J. y Mora Jiménez, H. (2009). Por una economía orientada hacia la reproducción de la vida. íconOS, 33, 39-49

Hopp, M. y Frega M. (2014). Economía popular, economía social y condiciones de vida: posibilidades y límites del Programa Ingreso Social con Trabajo "Argentina Trabaja”. En Cabrera, C. y Vio M. (Coord.). La trama social de la economía popular, Buenos Aires: Espacio Editorial.

Katime Orcasita, A. y Sarmiento, A. (2006). Hacia la construcción del derecho solidario en Colombia. Bogotá, Colombia: Universidad Cooperativa de Colombia- DanSocial.

Magnani, E. (2003). El cambio silencioso: Empresas y fábricas recuperadas por los trabajadores en la Argentina. Buenos Aires: Prometeo Libros.

Mance, E. (2001). La revolución de las redes. Petrópolis: Vozes.

Meira, D. A. (2013). A lei de bases da economia social portuguesa: do projeto ao texto final. Revista jurídica de economia social y cooperativa, CIRIEC, 24, 1-32.

Monzón, J. y Chávez, R. (2007). La economía social en la Unión Europea. Informe elaborado para el Comité Económico y Social Europeo por el Centro Internacional de Investigación e Información sobre la Economía Pública, Social y Cooperativa (CIRIEC).

Presta, S. (2016). El gobierno de lo posible. Economía social y solidaria, sujetos y poder. Revista Mexicana de Ciencias Políticas y Sociales, 61 (227), 349-378. 
Ruggeri, A., Alfonso, D. y Balaguer, E. (2017). Bauen: el hotel de los trabajadores. Buenos Aires: Callao.

Vuotto, M (2011). El cooperativismo de trabajo en la Argentina: contribuciones para el diálogo social. Lima: OIT/ Programa Regional para la Promoción del Diálogo y la Cohesión Social en América Latina.

Wisner, B., P. Blaikie, Cannon, T. y Davis I. (2004). At risk: natural hazards, people's vulnerability ad disasters. London, UK: Routledge.

\section{Legislación}

Ley 13136 de Actividades Laborales de Autoempleo y Subsistencia de la provincia de Buenos Aires.

Ley 10151 de Promoción y Fomento de la Economía Social de la provincia de Entre Ríos.

Ley 8435 de Promoción de la Economía Social y Solidaria de la provincia de Mendoza.

Decreto 2.266 de 2013 de la Provincia de Mendoza, reglamentario de la Ley 8435 de la provincia de Mendoza.

Ley 4499 de Economía Social - Mercados Asociativos de la provincia de Río Negro.

Ley 14650 de Creación del Sistema de Promoción y de la Economía Social y Solidaria de la Provincia de Buenos Aires.

Ley 7480 del Chaco de creación del Sistema de Promoción y Desarrollo de la Economía Social y Solidaria .

Ley Nacional 27345 de Emergencia Pública.

Decreto 159 de 2017, reglamentario de la Ley Nacional 27345. 